\section{The Maker Movement and the Louisville Free Public Library}

\section{Nicole Dixon and Michael Ward}

Nicole Dixon is a Community Outreach Supervisor and Michael Ward is Community Outreach Coordinator at the Louisville Free Public Library, Louisville, KY.

Correspondence concerning this column should be addressed to Eric Phetteplace, Systems Librarian, California College of the Arts, 5212, Broadway, Oakland, CA 94618; email:ephetteplace@cca.edu.
I have wanted to publish a column on Makerspaces for a while now, as they are such wonderful examples of the intersection of libraries, community, and technology. The 2013 LITA Forum in Louisville, which featured many concurrent sessions on making (including a session featuring one of the authors of this column), provided the impetus to find librarians willing to write about their experiences. Louisville Free Public Library has been a leader in collaborating with local Maker groups, and I hope other libraries can benefit from their advice.-Editor

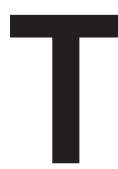

he Maker Movement at the Louisville Free Public Library (LFPL) started small, very small-in fact, with a pager motor, watch battery, and head of a toothbrush. A large group of teens and three librarians spent an afternoon soldering together these ingredients into small, simple robots that crawled slowly across a table and around in circles or that collided into each other. The kids debated how to make the machines work better and go faster and how to stabilize them during crashes. They shared what they were learning with each other and worked together to help their peers who were struggling. Everyone involved left thinking: We have to do more of this.

Actually, we say that is when it started, but really it started with a conversation in a coffee shop between those same librarians and one of the leaders of the local Maker Movement in Louisville who founded LVLl Hackerspace. He shared advice and ideas, and he recognized the library as a potential partner in furthering the movement in Louisville. LVLl would go on to partner with us for several events and even donate three 3D Printers to LFPL, by far the most popular item in our Maker toolkit.

Prior to the simple robot initiative, the library was doing Maker-style programming, but after the coffee shop meeting, the library became more intentional in its effort to provide these kinds of hands-on learning opportunities.

Initially, the effort was focused on a teen audience. The library was awarded a Broadband Technology Opportunities Program (BTOP) grant and used part of the funds to hire a community outreach coordinator, tasked with reaching out to local schools and community organizations and creating new technology workshops for teens. The programs needed to be interactive, engaging, tech focused, and offered at all eighteen branches of LFPL. The BTOP team came up with the Make Lab-a selection of gadgets and software that fit in a couple of wheeled cases outfitted with insulation to protect the equipment. Early programs focused on these broad categories: photography and image manipulation, filmmaking, video game creation, and other forms of digital storytelling. 


\section{ACCIDENTAL TECHNOLOGIST}

With experience and new staff, programming expanded to include new technologies like 3D modeling and printing, microcontroller kits, Arduino kits, and coding.

Something else that happened: we noticed that even though the programs were designated "teen," adults and families were showing up as well. The audience for these types of programs was diverse and quite large. To meet the growing demand, new programs have been added and older programs reworked to reach a broader audience.

\section{MAKER, MAKER MOVEMENT, MAKERSPACE}

This is how Maker Media describes a Maker: "Whether as hobbyists or professionals, makers are creative, resourceful and curious, developing projects that demonstrate how they can interact with the world around them."1 Deemphasizing the leader's role in the classroom is important. With all of our programs, we did not want a room full of people sitting quietly listening to a PowerPoint presentation. The instructor's purpose is to create the environment, be available for guidance, and provide tools that allow the participants to express their creativity by both demonstrating and interacting.

Remember that you do not have to be an expert at everything before you can start offering Maker programs in your library. A variety of resources exist to get you started. The Maker community thrives on collaboration, and a robust source of resources is readily available. Here are a few free resources to get you started Making:

- Computer Programming and Coding: Codecademy, Codepen, GitHub, free courses at CodeSchool.org, and Khan Academy²

- 3D Modeling and Printing: Autodesk 123D, Blender, MeshMixer, OpenSCAD, ReplicatorG, Sketchup, Tinkercad, and Wings 3D 3

- Games: Game Salad, PyGame, Scratch, and Sploder ${ }^{4}$

- General Making: MakerEd and DIY.org ${ }^{5}$

\section{MAKE MESSES, MISTAKES}

Having an open mind and focusing on self-guided learning and exploration are crucial to the success of any Makerspace. Proceeding with trial and error, learning from mistakes, and celebrating success are important when continuing to engage participants at every level of expertise. Here are some other lessons we learned:

- Maker education is an ongoing process. Focus should be on designing outcomes that measure learning, not end products.

- Work together and learn from the experience of your patrons. Participation in programs ranges from beginners to folks who know a good deal more than we do in the subject. The great thing about that is that they are usually willing to share their expertise.
- A one-to-one, hands-on approach is crucial when keeping anyone engaged. To overcome cost, encourage group work or offer repeat sessions.

- Learning is problem/solution based: the best way to learn is to learn how to clearly identify the problem that needs to be tackled (i.e. what a specific design should be, or how you want a webpage to look) and develop achievable solutions.

- Have a plan for what you want to accomplish, but always be flexible to accommodate the learning needs of participants.

- Maker librarians do not need to be expert builders, machinists, and software developers, but instead professional learners with an unending desire to learn and experiment with new things.

\section{FIND THE RIGHT FIT}

The term Maker feels like new branding for age-old concepts. The types of activities that qualify a person as a Maker range from crafts, to cooking, to writing software, to building machines or computers. Maker projects can be group activities, led by an instructor, or individual activities. Maker education can be held in a dedicated space, a multi-functional meeting space or classroom, a lawn, or even at a table in your library. The great thing about Making is that there is usually more than one way to achieve a goal, and figuring out what works for you is part of the fun. Though are no specific models set in stone, most Makerspaces fall into one of the following categories.

\section{DEDICATED/ENTERPRISE}

Examples: TekVenture, Maker Lab, YouMedia, 4th Floor, and HiTech $^{6}$

Enterprise Makerspaces have a dedicated, physical space in the library to house equipment and a dedicated staff to develop curriculum and implement programming. Makerspaces of this variety include a high profile and impact in their community but also carry a high overhead. Enterprise Makerspaces are often funded with federal innovation grants such as the IMLS Sparks! Grant, privately, or institutionally through the friends of the library.

\section{TRAVELING OR WHEEL-OUT}

\section{Examples: Make Lab (LFPL)}

Traveling or wheel-out spaces are more flexible in scope and a good fit for libraries with a multi-purpose meeting room. Traveling Makerspaces can also accommodate library systems with multiple branches and can be used as an outreach tool. Wheel-outs can range from things like small Maker programming kits containing a variety of gadgets, a set of laptops, and 
educational technological peripherals like digital drawing pens, electronic keyboards, and filming equipment. Similar initiatives of this variety are also helpful if a Makerspace already exists in your community, and it can allow the library to become a partner to share resources and educators.

\section{ONLINE}

Examples: Stereogranmator, Software Lending, App Library ${ }^{7}$

Often a result of digital collections, open-source data streams (open API, census, genealogy, or statewide GIS data), or software products, online Makerspaces usually engage the participants through distance learning and result in an interactive product. Online Makerspaces often employ crowd sourcing as a means for development and education. To kick start a product or app, try hosting a hack-a-thon in your community. Online Makerspaces offer a great tool to engage tech start-up businesses with library resources.

\section{MAKER INITIATIVES IN LIBRARIES}

There are libraries out there that allow you to check out a plot of land to learn food literacy, libraries offering cooking classes, fine arts classes, yoga instruction, and so much more. If you can think of it, then there is probably some library out there offering an opportunity for patrons to learn it. When you take a look at what libraries do today, it is easy to fit Maker education into that picture. For those who still see the library as just a book depository, it might be a bit of a stretch.

At LFPL, our Maker programs are a part of the broader educational initiatives that support our mission. Our library (LFPL) has the Job Shop, a center that brings LFPL's employment and career resources and the assistance of LFPL staff into a single service. The College Shop at the Shawnee Library is a "one stop shop" for prospective college students of all ages. We offer short courses, taught like real college courses by professors and experts in their fields, as well as our daily library-led classes. These daily classes focus on everything from literacy foundations for preschoolers to digital literacy for seniors and everything in between.

Libraries offer early exposure to new technology and can inspire patrons to explore a new skill that could become a personally satisfying hobby or even a highly desired job skill. A perfect example is computer coding and web development. Libraries could create a code club or help support community development initiatives. LFPL was able to purchase a subscription to the online learning platform Treehouse. It is freely available to anyone with a library card, but it is also used by Code Louisville, ${ }^{8}$ a local collaboration between economic development organizations, the library, and others to increase the number of software developers in Louisville and connect them with jobs.

Library Maker educators demystify things like coding without being expert coders. Library educators are experts at finding resources for education and make learning accessible. It is a truly collaborative effort between the person leading program and the participants.

\section{COMMUNITY COLLABORATION}

Last but not least, it is important to identify partnership opportunities. By partnering with other agencies like community centers, scout troops, colleges and universities, and tech schools, you can band together to create a more holistic Maker educational movement, providing access to exciting learning to your community. LFPL partners with outside organizations for public programs, such our partnership with the Louisville Digital Association (LDA) and LVL1 Hackerspace for a day of 3D printing workshops and demonstration. Louisville's inaugural Mini Maker Faire in September of 2013 was the culmination of work on behalf of LVL1, University of Louisville's JB Speed Engineering School, the KY Science Museum, LDA, the Louisville Free Public Library, and independent makers from across the state to introduce and celebrate with 15,000 participants. In smaller service areas, the library can be a Maker oasis. Seek out talented local individuals who are willing to share their time and talent.

\section{References}

1. Makermedia, Leading the Maker Movement, accessed June 5, 2014, http://makermedia.com.

2. Codecademy, Codecademy: Learn to Code Interactively, for Free, www.codecademy.com; Codepen, Build, Explore, and Teach the Web, Instantly, http://codepen.io; Github, Build Software Better, Together, https://github.com; Codeschool, Learn By Doing, www .codeschool.com; Khana Academy, Computer Programming, www.khanacademy.org/computing/cs.

3. Autodesk 123D, Get Started in 3D Printing and 3D Modeling, www.123dapp.com; Blender, 3D Creation Pipeline for Artists and Small Teams, www.blender.org; MeshMixer, http://meshmixer .com; OpenSCAD, The Programmers Solid 3D CAD Modeller, www.openscad.org; ReplicatorG, Simple, Open Source 3D Printing SProgram, http://replicat.org; Sketchup, The Easiest Way to Draw in 3D, www.sketchup.com; Tinkercad, Mind to Design in Minutes, https://tinkercad.com; Wings 3D, A Polygon Modeler, www.wings3d.com.

4. Game Salad, Create Games Rapidly Drag \& Drop, No Code, http://gamesalad.com; Pygame, Intro to Game Programming, www.pygame.org/news.html; Scratch, Imagine, Program, Share, http://scratch.mit.edu; Sploder4, Make Your Own Games Online, www.sploder.com.

5. MakerEd, Every Child a Maker, http://makered.org; www.you tube.com/user/MakerEdInitiative; DIY, Learn New Skills and Make Awesome Friends, https://diy.org.

6. Allen County Public Library, http://tekventure.org/about; Chicago Public Library, http://cplmakerlab.wordpress.com; Chicago Public Library, http://youmediachicago.org; Chattanooga Public Library, http://chattlibrary.org/4th-floor; Howard County, MA http://hclibrary.org/hitech.

7. NY Public Library, http://stereo.nypl.org; Kansas City Public Library, www.kclibrary.org; Digital Public Library of America, http://dp.la/apps.

8. KentuckianaWorks, www.codelouisville.org. 